\title{
Experiences of community health nurses regarding father participation in child health care
}

Siw Alehagen, Monica Hägg, Maria Kalén-Enterlöv and AnnaKarin Johansson

\section{Linköping University Post Print}

N.B.: When citing this work, cite the original article.

Original Publication:

Siw Alehagen, Monica Hägg, Maria Kalén-Enterlöv and AnnaKarin Johansson, Experiences of community health nurses regarding father participation in child health care, 2011, Journal of Child Health Care, (15), 3, 153-162.

http://dx.doi.org/10.1177/1367493511403952

Copyright: SAGE Publications (UK and US)

http://www.uk.sagepub.com/

Postprint available at: Linköping University Electronic Press

http://urn.kb.se/resolve?urn=urn:nbn:se:liu:diva-70813 


\section{Introduction}

The importance of giving children the necessary prerequisites for a good childhood, including material, social and emotional circumstances, is crucial for a favourable start in life and also for their health and well-being as adults (WHO, 2004). The importance of father involvement in the upbringing of a child has been identified and studied in recent decades and the paternal role has become broader than that just of provider. The involvement of fathers has been shown to give desirable outcomes, e.g. reducing behavioural and psychological problems and enhancing cognitive and social development (Wilson 2010; Sarkadi 2008).

As in most countries, Swedish mothers have traditionally taken responsibility for bringing up the children in the family. Fathers have, however, gradually increased their participation in child care in recent decades (Plantin, Månsson \& Kearney, 2000). Becoming a father has been described as a transition which starts when pregnancy is determined and continues during labour, the new born period and then through the different stages during the growth of the child (Draper 2003, Nyström \&Öhrling 2004). This transition is also influenced by the social context in which fathers live, their personal characteristics and the relationship with their partner (Genesoni \&Tallandini, 2009).

Formal child health care ( $\mathrm{CHC}$ ) has been developed in most countries but is carried out in different ways (WHO, 2004). The focus of CHC is to support parents in their transition into parenthood, supply immunizations, follow the physical, social and mental development of children and give advice on breast feeding, weaning, child-rearing and other issues related to bringing up a child. In Sweden CHC has been developed over the last 80 years. It is provided free of charge and offered to all parents from the time of the birth until the child starts school 
at the age of six. Parents decide themselves if they want to take part in all that is offered, parts of it or none of it. Almost $100 \%$ of Swedish children are registered in CHC, indicating a high rate of confidence in the system (Lagerberg et al 2008).

The traditional family consisting of a mother, father and children continues to be the most common but they have also become more diverse. Therefore, health care must also be prepared to meet single parents and homosexual couples.

The results of Fägerskiöld's study (2006) indicate that fathers want to be involved and take part in the care of their children. Fathers pointed out that a good relationship with the nurse in CHC increased their participation in child care. Some fathers felt excluded when the nurse always turned to the mother during visits. $\mathrm{CHC}$ nurses are care-providers who meet parents regularly and have the role of facilitating parents in their transition to parenthood. It is therefore important to look at these meetings with fathers at $\mathrm{CHC}$ from the point of view of the nurses.

The aim of this study was to describe nurses' experiences of father participation in CHC.

\section{Methods}

A qualitative design with semi-structured interviews was applied. Phenomenology according to Giorgi $(1997,2000)$ was used for the analysis. The method is concerned with the lived experiences of individuals to give a description of their own experiences based on the participants' own words.

\section{Participants}

Nine Community Health Nurses working with $\mathrm{CHC}$ were purposefully selected. To be qualified for working in $\mathrm{CHC}$ in Sweden nurses have to have specialist education, advanced 
level, in public health or paediatric nursing. A minimum of two years experience from $\mathrm{CHC}$ was required and $\mathrm{CHC}$ nurses in both urban and rural areas were selected. The nurses were aged between 37 and 64 (Median 49) and they had worked within CHC from 4 to 18 years (Median 9). Many of them also had experience from working in children's wards in hospitals.

\section{Procedure}

Written information about the study was sent to CHC nurses working at five Primary Health Care Centres in south east Sweden. They were informed that participation in the study was voluntary, that they could withdraw at any time and that they could choose the location for the interview. Oral and written consent to participate in the study was obtained from each participant.

A pilot interview was performed and after careful examination it was included in the study. All the participants chose to be interviewed at a $\mathrm{CHC}$ clinic. The interviews were conducted in a private room and $\mathrm{MH}$ and $\mathrm{M}-\mathrm{KE}$ performed half of them each. They were audio-taped and lasted between 30 and 60 minutes. The interviews were performed in July and August 2009.

The interviews opened with the following question: Can you tell me how you experience father participation in child health care? Participants were encouraged to speak freely about their experiences. The following questions were asked with the aim of deepening the conversation; would you like to tell me more? Can you explain? Can you give an example? The interviews were transcribed verbatim.

Permission to perform the study was given by the heads of the participating CHC clinics. The University involved in this study granted ethics approval.

\section{Analysis}


The analysis was performed according to Giorgi (2000). First the text was read and re-read with an open-mind to get a sense of entirety. Meaningful units were then selected and marked according to phenomena. These units could be a fraction of a sentence or a longer section. Units were first selected separately by two of the authors (MH and M-K E). They then discussed their selection and agreed upon a final list of units. Another author (SA) was then brought into the discussion on selection and consensus was reached. These units were then transformed from spoken language into professional caring language. This was done by the authors individually considering each unit and then conversing with each other. The final step was to synthesize and put the meaningful units into themes and then the essential structure, the essence, was clarified. The analysis is described in Table 1.

Table 1. Description of analysis of the interviews

\begin{tabular}{|l|l|l|}
\hline Meaningful units & $\begin{array}{l}\text { Transformation to } \\
\text { professional language }\end{array}$ & Themes \\
\hline $\begin{array}{l}\text { "I see the fathers sitting on the } \\
\text { floor with their children/...the } \\
\text { fathers play with their children } \\
\text { the mothers do too sometimes } \\
\text { but it seems that the fathers are } \\
\text { better at playing. The fathers sit } \\
\text { and drive cars with the children } \\
\text { and joke around with them" }\end{array}$ & $\begin{array}{l}\text { Fathers sit on the floor at the } \\
\text { CHC centre and play with their } \\
\text { children in a different way from } \\
\text { mothers }\end{array}$ & $\begin{array}{l}\text { Participation is equal yet } \\
\text { diverse }\end{array}$ \\
\hline $\begin{array}{l}\text { "adjusting appointments so that } \\
\text { he can participate if he shows } \\
\text { an interest of course yes so that } \\
\text { you don't force them but, like, } \\
\text { lead them forward" }\end{array}$ & $\begin{array}{l}\text { Adjusting appointments for } \\
\text { fathers who want to participate } \\
\text { strengthens participation }\end{array}$ & $\begin{array}{l}\text { Support which strengthens } \\
\text { participation }\end{array}$ \\
\hline
\end{tabular}




\section{FINDINGS}

The essence which emerged from the analysis was; father participation was seen from the perspective of mother participation and was constantly compared to mother participation in

CHC. The essence is explicated in the following themes; Participation through activities, Equal participation although diverse, Influence of structures in society and Strengthening participation.

\section{Participation through activities}

The nurses experienced the fathers as active when they came to the routine check-ups at CHC. Father participation was seen in activities like those of the mothers such as dressing and undressing the children, weighing and measuring height and asking questions. They had good knowledge of the children and the nurses received the information they needed. Fathers also participated in visits for immunisations and scheduled medical examinations of the children. Fathers phoned the $\mathrm{CHC}$ to ask questions and book appointments.

"They dress and undress the children and when we ask how the children sleep they can tell us as well as the mothers can. They tell us about mealtimes as well as the mothers, they know how long the child has coughed, if the child has a temperature, they know about these things. ”

In immigrant families many of the fathers were interpreters for the mother and nurse. Their focus was mainly on the communication and not on taking care of the child. Many nurses' experiences were that father participation in immigrant families had increased and this was most obvious when the mother had language problems. 
The nurses experienced it as natural when the fathers came alone with the children. Reasons for why the mothers did not come to a check-up could be that they were not well, they needed rest, they were at home with siblings or they had started to work outside the home.

\section{Equal participation although diverse}

Father participation was compared to mother participation. One aspect which arose was differences in communication. The nurses sometimes experienced that it was easier to talk with the fathers than it was with the mothers. The fathers had a more clear and direct way of speaking. Their way of communicating made the visits calm and safe and overall more gentle. They also stated that fathers tend not to repeatedly discuss different issues as some mothers do.

"In the newborn stage of parenthood I do not think that men sit and discuss at length the same issues with each other, such as nappies and how to do this and that, in the same way as women do,

The nurses described fathers as being focused on different topics from the mothers, they had other reflections and questions. They were asking for in-depth information about subjects like child development and nutrition and they did not want abstract answers. They were more critical about recommendations made by the $\mathrm{CHC}$ and wanted more information.

"The fathers want more in-depth information. When talking about nutrition and its importance they want to talk about vitamins and minerals.

The nurses also experienced that both mothers and fathers played with their children but they did so in different ways. The fathers were more physical in their playing and the nurses saw it 
as more exciting for the children. These activities were mixed with calmer play. The fathers sometimes were so engaged in playing that they forgot what was happening in the examination room or to look after siblings who were with them. This was interpreted by many nurses as the situation was less filled with demands whereas the mothers were more tense and wanted the children to behave well.

" The mothers are more careful careful, oh poor you poor you whereas fathers are not so cautious..."

Another aspect that differed between fathers and mothers was their behaviour when the child was vaccinated. Fathers were often calmer and they held the child in a relaxed way and the situation was therefore less strained. Some nurses were of the opinion that this was due to a higher rate of fear of injections among mothers.

\section{Influence of Structures in Society}

Then nurses perceived that changes in society, such as paid parental leave, had increased the possibility for father participation in CHC. Nowadays it is legitimate for fathers to participate in CHC starting with the first home visit, made by the nurse when the child is newborn, and continuing until the child is around six years of age. Still, they experienced that some fathers never came to $\mathrm{CHC}$ resulting in difficulties for the nurses to get an overall impression of the family and the child's situation.

The experience was that it is crucial for both parents to be present during the home visit as this could strengthen the father participation in the long run. The participation later on was dependant on aspects such as working and financial situations. Fathers often tried to get off from work to come to the $\mathrm{CHC}$ and the nurses tried to offer visits at hours which facilitated 
father participation. Father participation was also described as a movement among men in the way that many fathers related their visits to the fact that other fathers participate in CHC.

"There are few families where only the mother takes parental leave, it's common that both parents share it".

\section{Strengthening participation}

The nurses' perception was that fathers have an important role to fulfil in CHC and therefore it is a goal for nurses to get to know the fathers and to increase their participation. The default of supporting father participation was that the primary focus for the nurses was the mothers and the children. Many nurses stated that they used to turn to the mothers as they saw them in the first position in the care of the child. This was manifested in their failure to engage and support father participation as much as the mothers in conversations and examinations.

Support of the fathers could be shown by turning to them in conversations, listening to them and being open for their insecurities. Some nurses were of the opinion that participation of the becoming fathers is more obvious in antenatal care due to the excitement of the delivery and the new baby. The climax, the birth of the child, will after a while be ordinary weekdays when the mothers mostly are at home with the child and there is a risk that the desire of the fathers to participate in child care decreases.

The nurses' experiences were that if they wanted to support father participation they had to help fathers to be themselves and give them confidence in their actions. They experienced that some fathers came to the clinic with instructions from the mothers about what to say and how to behave. Some nurses described how they failed to support these fathers because they tended to act controlling towards the fathers. 
The nurses discussed that social support of parents had increased during the last decades and they described how the psychological health of mothers had come more into focus. Some nurses had met fathers who needed to talk about their own need for psychological help and they stressed the importance of paying attention to the well-being of the fathers. Their opinion was that considering the psychological health of fathers as well as mothers is a way of supporting parents in their care of the child, and in the long run strengthening father participation in $\mathrm{CHC}$.

The fathers are so important and we try to tell them that... some fathers are very frightened and insecure. They are afraid of showing their weaknesses and that they perhaps do the wrong things.

\section{Discussion}

We used a phenomenological method as we wanted to invite $\mathrm{CHC}$ nurses to provide their experiences of father participation in $\mathrm{CHC}$. The method is based on a limited number of informants which is a strength regarding the depth of the content but also a limitation regarding the possibility of generalising findings. Another limitation regarding the generalising of findings is the different national systems of parental leave for fathers.

In the described experiences of the $\mathrm{CHC}$ nurses four themes were found: Participation through activities, Equal participation although diverse, Influence of structures in society and Strengthening participation. Together they formed the essence in the result which was that father participation was seen from the perspective of mother participation and was constantly compared to mother participation. 
The perception of the $\mathrm{CHC}$ nurses was that father participation in $\mathrm{CHC}$ was of great importance and they tried to facilitate this by adjusting their way of working to establish relationships with the fathers. However, they always used mother participation as a reference when father participation was discussed and evaluated. Benzies et al. (2008) showed in their study that $\mathrm{CHC}$ nurses can be effective in implementing programs to empower fathers in their parenting role. They have both the opportunities and the skills for doing this. This is also emphasized by Sarkadi et al (2008) who recommends all professionals working with children and their families to enquire about and actively encourage the engagement of the fathers. Actively inviting fathers to join the children when it is time for health-care related visits is especially pointed out. Hallberg et al (2005) have shown that CHC has developed and a more family oriented approach has emerged indicating signs of adaptation to a changing family life in society.

One theme that emerged was "participation through activities". Participation was looked upon as visible actions showing that fathers wanted to take part in a new role. These findings were in compliance with Nyström \& Öhrling (2004). When participation by fathers of non-Swedish origin was described a diversified picture came up. These fathers focused on the contact with the CHC nurse and left the caring of the child to the mother. The nurses turned to the fathers when they asked for information about the child which is opposite to the situation when the parents were Swedish. According to Premberg et al (2008) this contributes to the Swedish fathers feeling of being excluded.

The different experiences of participation among the nurses might be due to their different ways of defining participation. This was also found in Coyne's study (1996), who found that participation can be seen as a relationship between the nurse and the parents which is built on mutuality. The relationship includes negotiations, control, intent, competence and autonomy. 
However, father involvement in $\mathrm{CHC}$ must not be equalized with their involvement in the child on the whole.

The second theme was "equal participation although diverse". The nurses saw father participation as equal but still different from mother participation. They also said that the fathers had a self-evident role in CHC. They made the children feel secure. Deave and Johnson (2008) have also described how mothers and fathers influence their children in different ways.

The nurses described how fathers asked different questions compared to the mothers and also that they asked in a different way. They were more direct and were sure about their questions. Like in Fägerskiöld's study (2008) the nurses felt that the fathers wanted to participate in the dialogues at $\mathrm{CHC}$. The staff working in health care has been shown to have a key role in supporting men in the transition to fatherhood (Genesoni \& Tallandini, 2009).

The CHC nurses described the role of the fathers as strong and supportive for both children and the mothers when the visits involved immunizations. These visits were considered frightening for the mothers and sometimes also for the fathers. A good relationship and a social communication between the parents and the nurse contribute to a less stressful situation for the child. The nurses in this study saw that the fathers took responsibility in this situation. Corresponding findings are described by Fägerskiöld (2008) and Premberg et al (2008). This might be a result of the earlier almost total female milieu in $\mathrm{CHC}$ and when a man enters the arena he becomes the brave one, reflecting traditional gender roles.

The fathers' way of communicating and taking care of the children was, according to the nurses, of great importance for the children. The fathers seemed to be able to focus on their children and disregard the surroundings when they played and took care of the children. They dared to play with them and were more active in their play. The mothers seemed to take 
another approach during the $\mathrm{CHC}$ visits; they were calmer and more focused on the health check-up. This was also shown by Premberg et al (2008).

The third theme dealt with how the structure of society influences father participation in CHC. One example is the fathers' possibility to paid leave for taking care of their child. This can be seen as a sign in society showing that it is acceptable for the fathers to take an active part in bringing up the child, also shown in Dribe \& Stanfors (2009) and Plantin et al (2000). Father participation increases when the children grow older, probably because the mothers go back to work when breastfeeding is ended. The nurses felt that in many families the financial situation influences how the fathers can use the parental leave. This is in concordance with results from Lammi-Taskulas (2008). Furthermore, the parental insurance system in Sweden has changed from "mothers' insurance" to "parental insurance". For many years the parents have had the opportunity to share parental leave between them and since 1995 there are special days allocated to the father, which the mother cannot use. This leave will be lost if the father does not take it. In 2008 the fathers took $21 \%$ of the total parental insurance days (The Swedish Social Insurance Administration, 2009).

The fourth theme "Strengthening participation" covered the experiences of nurses concerning the fathers' need of support in their transition into parenthood. This was important to make them feel secure in their new role and want to participate in CHC. This is emphasized in several studies (Nyström \& Öhrling 2004; Fägerskiöld 2008; Ny et al 2008). However, earlier studies (Baggens 2001, Runeson et al 2002) showed that nurses were used to turning to the mothers in their interviews and counselling and hence often excluded the fathers. This might have affected father participation negatively. The nurses of this study were aware of their 
failure to include fathers as much as mothers, they did not turn to the fathers in conversations for example. They also felt that mothers, sometimes, wanted to manage by themselves.

The need of individual support for the fathers was shown by Berlin et al (2006) and the mothers' first position having carried the child during pregnancy and feeding the child during breastfeeding probably explains this. Fägerskiöld (2008) describes the fathers' feeling of estrangement when the child is breastfed.

Fathers seemed to need extra support when they had to go back to work. They needed to be convinced that this was natural (Deave \& Johnson 2008). This was found to be difficult for nurses and they felt that they had to cut off their relationship to the fathers. However, society is changing and it has to become natural for the $\mathrm{CHC}$ nurses to have contact with both parents during the child's first years, some periods more intense with the mother and some with the father. The traditional roles of the parents, mother taking care of the children and the father responsible for providing for the family, are changing and this has to be realised by CHC (Dribe \& Stanfors 2009). In the caring of the child the parents are equal, different but complementary.

A special situation is when the child lives alternatively with the mother and the father. Then it is important for $\mathrm{CHC}$, together with the parents, to find ways to have contact with both the mother and the father. Both of the parents should get first hand information.

Social support tends to be of increasing importance for families. Both this study and Hallberg et al (2005) have shown that CHC has adapted to this. Screening for postnatal depression among mothers has been included in the routines at CHC in Sweden (Lagerberg et al 2008) and it is under discussion if this screening also should include fathers. Becoming a parent is a stressful transition and better support from $\mathrm{CHC}$ could prevent both poor mental health and 
divorces. Ahlborg and Stenmark (2001) saw that mothers excluding fathers from child care as possibly contributing to poor mental health among the fathers.

It is important for $\mathrm{CHC}$ to follow and adapt to changes in society such as mothers and fathers sharing childcare equally regardless if they live together or apart from one another. Mothers increased frequency of professional work outside the home and the debate in society on gender equality have contributed to this. There are also families with only one parent, mother or father and families with two male or two female parents. The $\mathrm{CHC}$ nurses seemed to be aware of this but still work mostly traditionally with activities formulated for a nurse/mother contact. Communicating directly with the fathers is essential in ensuring fathers' involvement. In the specialist training for $\mathrm{CHC}$ nurses an increased competence for including fathers should be stressed. An interventional study (Lagerberg et al 2008) focusing on psychosocial support in $\mathrm{CHC}$ has almost entirely focused on the mothers. Creating a changed context for the work in $\mathrm{CHC}$ is important. Further research and following interventions to increase preparedness for meeting fathers and non-traditional families in $\mathrm{CHC}$ is required.

\section{Conclusion}

The CHC nurses saw father participation in $\mathrm{CHC}$ in comparison to mother participation. It was considered to be different but equal. They also described the need of creating a separate identity in $\mathrm{CHC}$ for the fathers and more communication directed at the fathers.

\section{References}


Ahlborg, T. \& Stenmark, M. The baby was the focus of attention - first-time parents' experiences of their intimate relationship. Scandinavian Journal of Caring Science 2001; 15: 318-325

Baggens, C. What they talk about: conversations between child health centre nurses and parents. Journal of Advanced Nursing 2001; 36: 659-667

Benzies, K., Magill-Evans, J., Harrison M.J., MacPhail, S., Kimak, C. Strengthening New Fathers' Skills in Interaction with their 5-month-old Infants: Who Benefits from a Brief Intervention? Public Health Nursing 2008; 25: 431-439

Coyne, IT. Parent participation: a concept analysis. Journal of Advanced Nursing 1996; 23 : 733-740

Deave, T. \& Johnson, D. The transition to parenthood: what does it mean for fathers? Journal of Advanced Nursing 2008; 63: 626-633

Draper J. Men's passage to fatherhood: an analysis of the contemporary relevance of transition theory. Nursing Inquiry 2003: 10; 66-78

Dribe, M. \& Stanfors, M. Does parenthood strengthen a traditional household division of labor? Evidence from Sweden. Journal of Marriage and Family. 2009; 71:33-45

Fägerskiöld A. Support of fathers of infants by the child health nurse. Scandinavian Journal of Caring Sciences 2006; 20:79-85

Fägerskiöld, A. A change in life as experienced by first-time fathers. Scandinavian Journal of Caring Science. 2008; 22:64-71.

Genesoni, L. \& Tallandini M.A. Birth 2009; 36: 305-316

Giorgi, A. The theory, practice and evolution of the phenomenological method as a qualitative research. Journal of Phenomenological Psychology. 1997;28:235-261.

Giorgi, A. The Status of Husserlian Phenomenology in Caring Research. Scandinavian Journal of Caring Science.2000;14: 3-10.

Hallberg, AC., Lindbladh, E., Petersson, K., Rådstam, L., Håkansson, A. Swedish child health care in a changing society. Scandinavian Journal of Caring Science 2005; 19: 196-203

Lagerberg, D., Magnusson, M., Sundelin, C. Barnhälsovård i förändring: resultat av ett interventionsförsök.(In Swedish. A changing Child health care: results from an intervention) 2008 Gothia, Stockholm

Lammi-Taskulas, J. Doing fatherhood: Understanding the gendered use of parental leave in Finland. Fathering 2008; 6: 133-148

Ny, P., Plantin, L.,Dejin-Karlsson, E., Dykers, AK. The experience of Middle Eastern men living in Sweden of maternal and child health care and fatherhood: focus-group discussion and content analysis. Midwifery 2008; 24: 281-290 
Nyström, K. \&Öhrling,K. Parenthood experiences during the child's first year: a literature review. Journal of Advanced Nursing 2004; 46: 319-330

Plantin L, Månsson SA, Kearney J. Mäns föräldraskap - om faderskap i England och Sverige [Mens' parenthood - about paternity in England and Sweden]. Socialmedicinsk tidskrift 2000; 1-2:24-42 (in Swedish).

Premberg, Å., Hellström, A-L., Berg, M. Experiences of the first year as father. Scandinavian Journal of Nursing 2008;22: 56-63

Runesson, I., Hallström, I., Elander, G., Hermerén, G. Children's participation in the decisionmaking process during hospitalization: an observational study. Nursing Ethics 2002; 9: 583589

Sarkadi, A., Kristiansson, R., Oberklaid, F., Bremberg, S. Fathers' involvement and children's developmental outcomes: a systematic review of longitudinal studies. Acta Paediatrica 2008; 97: $153-158$

The Swedish Social Insurance Administration. (Försäkringskassan) Statistics. http://statistik.forsakringskassan.se/portal/page?_pageid=93,225621\&_dad=portal\&_schema= PORTAL 20100224

WHO. Development of National Child Health Policy Phase 1: The situation analysis. World Health Organization, Eastern Mediterranean Regional Office Child and Adolescent Health and Development Unit, Egypt 2004

Wilson, K.R., Prior, M.R. Father involvement and child well-being. Journal of Paediatrics and Child Health 2010; electr publ. 